\title{
The Value of Public Health Research and the Division Between Basic vs. Applied Science
}

Naomar Almeida-Filho and Moisés Goldbaum

\author{
Institute of Collective Health, Federal University of \\ Bahia, Salvador, BA; School of Medecine, University \\ of São Paulo, São Paulo, SP, Brazil
}

\begin{abstract}
We question the movement towards exclusion of population and social health research from the field of science. The background under analysis is contemporary Brazil, where the scientific field that hosts this kind of research is known as Collective Health. First, the problem is formalized on logical grounds, evaluating the pertinence of considering unscientific the many objects and methods of public health research. Secondly, the cases of pulmonary tuberculosis and external causes are brought in as illustrations of the kind of scientific problem faced in health research today. The logical and epistemological basis of different forms of "scientific segregation" based on biomedical reductionism is analyzed, departing from three theses: (i) the ethics of the general application of science; (ii) the inappropriateness of monopolies for objectivity in the sciences; (iii) the specificity of scientific fields. In the current panorama of health research in Brazil, a residual hegemonic position that defends a narrow and specific definition of the object of knowledge was found. The denial of validity and specificity to objects, methods and research techniques that constitute social and population research in health is linked to elements of irrationality in reductionism approaches. Nevertheless, efforts should be directed to overcome this scientific division, in order to develop a pluralist and interdisciplinary national science, committed to the health care realities of our country.
\end{abstract}

Key Words: Public health, collective health, basic sciences, applied sciences, science and technology policy, Brazil.

Many researchers with biological or clinical backgrounds have difficulties in recognizing as scientific the production of knowledge on health/disease outside the fields of the so-called natural sciences (strictly Physics, Chemistry or Biology, and respective subdisciplines). As a justification, a classification of science as pure or applied is often called upon to emphasize the notion that applied studies are not really science but, at most, they constitute mere applications of scientific research. In the recent literature on the

Received on 07 February 2003; revised 20 February 2003.

Address for correspondence: Dr. Naomar Almeida-Filho. Condomínio Jardim Piatã - Qd. 6 - Lote 3, Piatã, Salvador, Bahia-41650-200. Phone: 5571-263-7000.

E-mail: naomar@ufba.br

The Brazilian Journal of Infectious Diseases 2003;7(1):82-90 (C) 2003 by The Brazilian Journal of Infectious Diseases and Contexto Publishing. All rights reserved. history and philosophy of sciences, such a standpoint goes by the name of 'reductionism' [2,6,12,22].

Such a restricted perspective ends up expelling from the realm of science the intellectual patrimony and methodological repertoire of several fields of traditionally established knowledge, as for instance: (a) the whole science of Demography; (b) the field of Medical Anthropology; (c) the entire field of Health Economics; (d) the whole subfield of Human Ecology; (e) the whole area of exploratory clinical research; (f) the research area of Political Sciences applied to health; (g) the whole research area of Social Psychology applied to health; (h) much of Epidemiology (exceptions are molecular epidemiology and clinical epidemiology); (i) institutional micro-sociology (studies of organizations); (j) all of S \& T research in Health; (k) research on ethical, juridical and philosophical issues related to health. Some disciplinary fields may be 
considered as subsidiary or subordinate, recognized as mere auxiliary instruments for research, as for instance: (a) the subfield of Biostatistics; (b) Mathematics (essentially algebra and calculation); (c) Information Sciences and (d) Computation Sciences. The exclusionary movement promoting denial of a place within the scientific field for certain modalities of research ought to be challenged. The basic argument herewith is developed with special reference to a cluster of such disciplines, namely population and social health research. The background for this analysis is contemporary Brazil, where the scientific field that has hosted this type of health research is known as Collective Health. In other countries, this field has been designated as Public Health, Community Health or Social Medicine.

With this aim, first of all, we intend to formalize the problem on logical grounds, evaluating the pertinence of considering unscientific the many objects and methods of public health research. Secondly, we explore the logical and epistemological basis of different forms of "scientific segregation" based on biomedical reductionism, starting from three theses: (i) the ethics of general application of science; (ii) the inappropriateness of monopolies over objectivity in sciences; (iii) the specificity of scientific fields. Lastly, we identify elements of irrationality in reductionism approaches that purport to deny specificity to the objects, methods and research techniques that sustain the basic principles of social and population research in health.

\section{Problematization}

A reduced, yet influential, group of scientists postulates that only topics of physicochemical or biological nature deserve to be taken as valid objects of research. They contend that priority agendas in the health field should include only research themes largely considered as objective issues, such as physiopathology and molecular or cell biology of diseases, systems and tissue morphology, vector and pathogen biology, biochemistry and pharmacokinetics of substances with therapeutic effects and clinical research on diagnostic and therapeutic procedures. At the limit, and with reluctance, they sometimes accept that so-called clinical epidemiological research can have some (small) degree of scientific value. This thinking seems to continue hegemonic in the scientific community of the self-named Health Sciences, not only in the local context of Brazilian science but also in world centers of scientific production.

On the one hand, such a perspective identifies as valid research problems only tangible phenomena and events that are physically delimited and intuitively objective. In order to justify this position, this type of thinking reveals an empiricist and naturalistic (or substantialist) view of science [19,20]. By assuming such a posture, it faces an ambiguity and creates a paradox. Indeed, in common scientific rhetoric it is affirmed, reiterated and constantly declared that science is oriented to the solution of human problems.

On the other hand, such an approach recognizes only pathological phenomena as viable objects of research and prioritizes the study of isolated outcomes to the detriment of determination processes. Therefore, it also relies on the ancient assumptions that the world is structured by simplicity and fragmentation [24]. Because of this fragmentation bias, reductionism equally excludes any interdisciplinary or transdisciplinary depiction of science $[5,15]$. In a context of extreme competition, each discipline strives to reduce the other fields and levels to its own object and method, showing itself to be the only science with enough explanatory power to produce scientifically valid knowledge.

Non-physical, non-chemical and non-biological research topics compose precisely the subject matter of disciplines that form the scientific field generally designated as Collective Health or Public Health. Such disciplines are basically epidemiology, and a broad list of the humanities and social sciences applied to social, cultural and institutional processes and phenomena in the health field. Amplifying the logic described above, radical reductionism simply denies any "certificate" of scientificity to collective health research.

Is it possible to effectively get to know and to solve health problems using such a perspective? Consider a concrete example: pulmonary tuberculosis (Koch's 
disease). This is a pathology that is generally considered as solved as a scientific and technological problem. Research about the molecular biology of the pathogen or about the physiopathology of susceptible individuals, as well as better descriptions of the patient's clinical picture or development of new therapeutic schemes will add little to the available knowledge and technology for the potential biological control of the most frequent forms of the disease. Today, enough is known about the etiopathogeny and the clinical history of this disease to guide strategies and provide for effective interventions for its prevention and cure in almost all cases. However, in spite of this situation of advanced scientific and technological development, prevention and control programs have experienced continuing difficulties to make such knowledge and technology beneficial for groups at risk and patients in need of treatment for this disease. As a result, pulmonary tuberculosis remains endemic in most undeveloped countries and has reemerged in industrialized countries, still constituting an important public health problem all over the world [8].

Many other health problems could be mentioned in this regard, especially endemic diseases that still strike Brazil nowadays, such as dengue fever, cholera and Hansen's disease. However, the problem of pulmonary tuberculosis constitutes a most eloquent demonstration of the need to know and understand the concrete processes of human life submitted to the experience of illness, beyond just explaining material phenomena and mechanisms of cell life and intra-organic systemic processes. Actually, little is known about the bonds of tuberculosis patients' with institutions of health care in an open regime, about their symbolic relationships when facing a chronic pathology that turns asymptomatic with initial therapeutic measures, on the stigma associated with pulmonary tuberculosis diagnosis in different cultures and subcultures, on the effectiveness of alternative regimes of monitoring and control, on micro- and macro-economical impacts of the pathology and the endemic factors, and so on [16].

What is the logical basis of positions that justify exclusively biomedical research of, for example, pulmonary tuberculosis? There is none. Does it make any sense to deny scientific validity to questions that are important for the understanding of the reasons for the persistance of tuberculosis as a public health problem in Brazil? It makes no sense whatsoever. Though they seem to be obvious and sensible, these negative answers ought to be justified with some degree of methodological rigor and at least minimal epistemological consistency. In this regard, we analyzed a short series of general theses regarding scientific research.

\section{Method}

This analysis is intended to demonstrate the lack of validity of biomedical reductionism, confronting it with premises, arguments and illustrations. Thesis 1 emphasizes the issues of ethics and the purpose of inquiry in the health sciences; Thesis 2 approaches the topic of research focus on an objectively considered reality; Thesis 3 evaluates the subject matter of the nature and specificity of scientific fields.

\section{Thesis 1 . Ethics and utility of the health sciences}

Premise 1. Only health sciences potentially applicable to the well being of humankind are ethically justified.

Argument 1. The distinction between pure (or basic) science and applied science is intuitively refuted by verifying, in several scientific fields, the inadequacy of the concepts of basic and pure science, especially concerning the issue of the critical nature of the scientific endeavor. Besides, logically, the antagonism implicit in such a formulation makes no sense, inasmuch as the opposite of pure is impure, and never "applied". The opposite of basic can be accessory, supplementary, or even super-structural but never "applied". The adjective therefore does not seem to fit the semantics of scientific research. In actuality, this ethical imperative is applied even more forcefully in the field of biological research. Other "sciences of origin" help to compose general cosmologies, however the human reference is always central [20].

Illustration 1. When for instance one investigates the effect of a certain molecule on cerebral synapses, what is sought for is not merely to know more about 
that molecule in particular or about energy connection patterns between specific cells. In fact, what is intended is to produce some knowledge potentially applicable (now or in the future) for the solution of problems relative to the normal or pathological neural dynamics, improving the quality of life and health of subjects affected by such problems. Humans do not produce science about animals for the sake of the animals. Scientists are not at the service of the bacterium or the arteriole. Rather, they are committed to the human species and to human beings that suffer from bacterial infections or have damaged vascular systems.

Conclusion 1. Given that it is mandatory to prioritize scientific practices capable of supplying knowledge, as well as technological and pragmatic answers to facilitate human life in the ecosystem, it follows that all science is applied science, at least in the domain of life sciences.

Thesis 2. Objectivity of the health reality

Premise 2. One cannot distinguish processes, phenomena and events of health-disease, prima facie, for their supposed degree of objectivity or materiality.

Argument 2. To be considered as a scientific object is not just a privilege of tangible, palpable and ponderable processes, events and material phenomena. The exclusion of intangible, impalpable and imponderable objects from the field of science (which is another way of attributing an inferior status to forms of knowledge production different from the natural sciences) is neither logic nor pragmatically defensible. The principle of materiality as a criterion of scientificity was last defended 150 years ago by the physicist Lord Kelvin ("when you cannot see, touch, weigh or measure it, your knowledge is of a meager kind"). Since then, ironically, the sciences that work with matter (i.e. Physics and Chemistry) were the first to challenge the assumption that human senses are good sources of criteria to define whether something exists and to assign objectivity to scientific objects $[17,18]$.
Illustration 2. We can examine pain or suffering or a mother-son relationship, the ideology prevailing in health institutions or safe sex practices and the rhetoric of risk in social discourse; no matter how much these phenomena are defined as immaterial, subjective, symbolic and psychological, they can and should be taken as scientific objects as much as a radiation spectrum or a sample of volcanic ore.

Conclusion 2. All phenomena of nature and society deserve the opportunity to become an object of human scrutiny by the systematic and formalized methods of science.

Thesis 3. Specificity of scientific fields

Premise 3. The sciences are defined by their specific objects (subject-matter) and, mainly, by their specific methods.

Argument 3. Evidently coalitions and compositions in terms of an object of knowledge can be observed in the interfacing scientific fields, as for instance geophysics, biochemistry and ecology [13]. By the same token, one may find transpositions or interpenetrations of methods, as for instance sampling techniques or experimental designs, which are used by research fields as unrelated as political sciences and hematology. However, even considering hybrid objects and shared methods, the preservation of pertinence of object and method in a given scientific field is logically and theoretically justifiable [3].

Illustration 3. One cannot work with cells, the object of a branch of biology, as if they were black holes, object of astrophysics research. Nor can one investigate pathological processes as if they were equivalent to meteorological processes. In methodological terms, it will never be legitimate to use a method for monitoring diffuse electromagnetism originated from particle physics to evaluate biochemical phenomena, nor can the capture-recapture technique created for ecological field studies be used to investigate the trajectories of comets. 
Conclusion 3. In each case, under all circumstances, the specificity of the disciplinary fields of science should be respected.

\section{Results}

Given the central role of the problem of specificity of the scientific fields, Thesis 3 deserves a more detailed exam, particularly concerning its applicability in the field of social and population health research. This implies that we are taking theses 1 and 2 as premises for the axial thesis of scientific specificity. The key question in that regard may be formulated in the following way: will there be an object-problem of Public Health specific to a sufficient degree to justify the constitution of a particular field of scientific knowledge and technological application?

To move forward in the treatment of this question, it will first be necessary to understand in what sense specificity is defined and what are the possible manners to formulate the problem.

\section{Field Specificity (or Scientific Community)}

According to Pierre Bourdieu [3,4] scientific fields are not in fact determined by an assumed order of things that belong to the empirical world. That is, it is not the mere existence of diseased men and women that forcefully generates a science of disease called pathology; nor do storms, hurricanes and droughts determine meteorology. Rather, scientific fields are instituted through a praxis that articulates object and method, conception and practice, epistemological boundaries and social constrictions, structuring conditions and organized action. From this perspective, a distinction should be made between disciplinary field, field of technological application and field of social practices. Disciplinary field refers to the historical-social and institutional space predominantly occupied by the development of production processes and the application of scientific knowledge. Field of technological application indicates historical-social and institutional spaces defined by prevailing activities of the use of technological devices or procedures, typically with processes relatively structured and products/results accomplished with a reasonable degree of prediction. Field of social practices refers to the symbolic, historical-social and institutional space where semi-structured or unstructured processes of a communal or professional praxis, such as clinical medicine, are performed [10]. This distinction is based on the predominant, but never exclusive or monolithic, feature of a given social field. Therefore, a disciplinary field is strongly impregnated by social practices, and as well as fields of technological application, they have important effects on the process of production of scientific knowledge.

The constitution of a science does not result from disciplinary fields that interact amongst themselves but rather it emerges out of the concerted efforts of individuals and groups that build them in daily scientific practice ${ }^{6}$. Put this way, there is no such a thing as an empty scientific field, or at least fields that consist of abstract entities (principles, concepts, theories and models). The institutional spaces of science are permanently occupied by the subjects of science, historical agents, organized in peculiar social groups that have been called "scientific communities", structured in matrices of thought and conduct that correspond to the concept of 'paradigm', as coined by Thomas Kuhn.

As far as the analysis of scientific development is concerned, paradigms correspond to "scientific accomplishments universally recognized that, during some time, supply model problems and solutions for a community of a given science" [11]. According to this author, the scientific practice devoted to the completion of gaps and the production of answers to questions originated within an established paradigm is called normal science. In certain moments of crisis, there could be ruptures in the assumptions, concepts and values accepted by a scientific community. The paradigm crisis would favor the emergence of new scientific theories and even the development of new disciplines or interdisciplinary fields. This rupture constitutes what Kuhn [11,12] ended up designating as "scientific revolution." 
Without a doubt, this is the most sociologically robust approach to the issue of specificity of scientific practices. Nevertheless, it will probably be the least useful for the institutional and political dialogue that has come of age. We can advance gingerly in the demonstration that public health research already conforms to a structured community, with its own identity, critical mass, and organized institutional network.

The constitution of such an institutional network can be shown through the many organizations that, in Brazil, are under the mantle of Collective Health, composed of institutes/schools of collective health/public health/ social medicine, departments of preventive/social medicine and centers of collective health. These institutions form the field's academic base and are articulated with the policy-makers of the health sector, as well as health service providers, especially public institutions. The constitution of the different institutions is marked by different contexts and regional characteristics; thus, one can find institutions within the traditional Public Health sector; others are generated inside medical schools, trying to orchestrate movements for salvaging the old public health structure; others, although they emerged from medical institutions, stand out, creating new independent lines of thought. There are also regional hybrid nuclei, articulating different participants and scenarios of Collective Health.

This 30-year movement has mushroomed, especially in the last decade. Today, it hosts a critical mass of researchers corresponding to the growth of the institutional network, including almost 300 research groups, second in size in the health sector, only behind the sub-area of Medicine, according to the $\mathrm{CNPq}$ Directory of Research Groups - Version 4.0 [9]. Its research lines comprise a wide multidisciplinary range, which include, prominently, epidemiology as well as health planning and administration, and other human and social sciences applied to health. In this context, collective health research groups tackle study processes and the phenomena of health-disease-care in human populations, not as mere aggregates of individuals but involving an understanding of the dynamics of social relationships and forms of social organization.

\section{Specificity of the Level of Anchorage}

The domain of phenomena defined by science as part of its empirical field is not a monolith. In other words, the concrete objects of science are by definition multifaceted and complex [15]. This means that they are manifested in reality as plural processes and as phenomena that happen simultaneously at different levels of existence. Such a manifestation of the complexity of objects is verifiable in each and every scientific field. In health, this is even more so $[1,7]$. To continue with the example given above, we see that pulmonary tuberculosis is manifested at a cellular level (as a tissue lesion), at an intra-systemic level (as inflammatory functional alteration of the lung), at an individual level (as signs and symptoms - cough, fever, spittle), at a population level (as cases of the disease), all at the same time. In real time, for each population, there are cases with clinical manifestations of the disease; in each one of them, one can find an impaired physiology with systems and organs affected or damaged by the action of the microorganism.

To understand the multilevel character of complex scientific objects, the eminent Argentine epistemologist Juan Samaja [21] developed the concept of "level of anchorage". This concept implies that the structures of reality are hierarchical and that, in such a succession of levels, there will be a privileged (but not exclusive) domain of each level bound for the approach of systematic modes of knowledge. The object of knowledge, therefore, is structured in levels of anchorage, following hierarchical orders of complexity, with varied degrees of specificity, depending upon the object under investigation (for instance: subatomic particle, atom, molecule, substance, compound, ore, soil, geological formation; other examples include: sign, sense, text, narrative, context, speech, language). Each level is not exclusively constituted of the summation of the inferior levels; they have new qualities, provided by their own characteristics. When contemplating this dimension of verticality, the multiplicity of horizontal levels is increased, as recognized in the relationships of the different disciplines studying the same object. 
For what interests us, the specificity of the levels of approach of health sciences should be assumed by taking as a baseline the contexts (populationatmosphere-society) that distinguish them from the molecular or individual levels (organism). The subject matter of specificity of the level of approach therefore seems to be the most fruitful for the necessary debate at this time.

Let us take as example a possible hierarchical order in the biological field: molecule, cell, tissue, organ, system, organism, group, population, and environment. In the case of biological organisms usually designated as "human beings", who speak (that is, master an evolutionary tool called language) and are related in a structured way with their fellow creatures (in other words, are constituted as social beings), an important quality change happens. In that species in particular, supra-organism levels are unfolded in other possible orders, as for instance the symbolic order; so the human being, the series organism-group-populationenvironment can be replaced by subject-family-societyculture.

For scientists engaged in the area of health-disease phenomena, it is out of question to naively assume that human populations constitute a mere sum of individuals that, in turn, are just a functional articulation of organs and systems, formed by differentiated tissues that, in turn, are composed of biochemical micro-plants called cells, that finally are constituted of molecules. In this almost caricatured reference of reductionism, the definition of health-disease will be simple and linear. Disease implicates a chain of diverse phenomena occurring at different levels of existence; it is a defect in the molecular structure of cells, with a lesion at the tissue level, resulting in alteration of the function of organs and systems, producing pathology, which is objectively expressed as signs and symptoms in individuals that, accumulating in groups of sick individuals, constitute morbidity in populations. In this case, each of the disciplinary fields of applied human biology demands for its own the hegemony of the level that defines the health-disease object. Molecular biology takes the genome and the proteoma as the only valid themes of research, claiming that all other levels of pathological processes flow out of those basic systems of molecular and biochemical reproduction. Histopathology and immunopathology argue in favor of the centrality of tissular or intrasystemic levels in the causality of pathology, given that lesions and alterations constitute the causes of signs and symptoms that define objectively what disease is. Physiopathology, explicitly instituted as the basic science of clinical medicine, prefers to invoke models of regulatory mechanisms or pathological unbalances to concretely explain the causality of diseases, and therefore to dominate the object of knowledge.

On the other hand, when we approach such a problem with just a small amount of epistemological awareness, at least the objects "health" and "disease" can be considered complex, plural or multifaceted ${ }^{7,14,23}$, being simultaneously a defect, lesion, alteration, pathology, disease, risk, damage or illness, or correlates of such phenomena. In this case, the recognition of potential contributions of other scientific fields is always implied. Yet, on one hand, this recognition does not solve the problem of fragmentation of knowledge given that each one of the levels ends up being a dominated territory, earmarked as an intellectual sanctuary of one specific disciplinary field. On the other hand, such an apparently "liberal" approach barely hides a bias toward scientific hegemony, in the sense that each field would accept a contribution from another disciplinary field bound to a different anchorage level only if this is presented in a subordinate, colonized manner.

\section{Discussion}

As seen above, the radical reductionism approach simply denies any degree of scientificity to social or collective health research. Examples of such epistemological segregation multiply with the expansion and consolidation of the health field, distinguishing markedly from other scientific fields and sectors of social practice. Several conditions that are not technically classified as disease are now recognized as health problems. Let us now take socalled "external causes" as an example. We do need a broader conception of environmental hazards, 
violence and terrorism to have external causes justly included as a current major public health problem. This implies developing an entire new perspective for analysis and understanding of the subjects and victims of violence as well as the search for tools for knowledge building. Although recognizing that a neurobiology of violence (or an ecology of aggression) will be just a tiny piece of the big puzzle, nobody can deny the important role of social-cultural and political factors that determine this type of health problem. In this case, material and biological knowledge will be of little value to subsidize the definition of intervention policies.

Other examples stand out: new conceptions emerge in the field of geriatrics for understanding how everyday life challenges may become health problems for the elderly; emerging and re-emerging infectious diseases call for a broader comprehension of their dynamics, bringing new elements for their control in a world already plagued by chronic-degenerative conditions; the chapters of mental diseases or child-maternal health are enriched with new conceptions of social health and of gender, respectively. The same applies to the analysis of medical rationalities, which forms a field of inquiry completely different from that offered by clinical science or health service organizations. These examples reveal that new forms of definition of health-disease problems and their correlates have to be considered, different from traditional ones, as for instance the clinical approach that typically finds in the individual level its maximum degree of accomplishment, or the physiopathological approach that focuses on the sub-individual level. Such examples demonstrate as well that the construction of analyses at the population level demands specific objects and methods that might encounter fully adequate means for the production of knowledge only in the epidemiological and social sciences.

It is of general agreement that health is by definition complex, contextual and historical. Researchers also may have come to terms with the impossibility of applying universal protocols of validation and of defending pre-fixed, determined and structured explanatory models for generating knowledge about all health matters. Health is by definition applied. Research practice in public health is thus defined by a vocation or a commitment with the transformation of health situations. Researchers in this area should be committed and embedded - in the sense of being integrated and deeply engaged (not merely in a militant sense), without estrangement for being in permanent dialogue with the groups and populations. In contrast, in the biomedical sciences the object disease is predominantly presented as an entity that results from autonomous processes, independent from the life of the sick people [1].

These considerations on the nature of the objects health and disease are little applied to the health and the biomedical sciences. Nobody wins with a prejudiced vision of the biological sciences, considering that the object disease also can (and must) be defined in a historical, contextual and pragmatic sense. Excessive simplification of the complexity of pathological processes is not advantageous even for the most conventional practice of biomedicine (and for the clinic, in its activity of etiological and therapeutic inquiry). It is necessary to cultivate a "complementing" perspective, given that one can go beyond the level of anchorage of a given discipline to approach pathologies and health states or situations to take advantage of the strengths and to restrict the limitations of different scientific focuses, respecting each one's pertinence and adequacy. Also, this implies that an expanded concept of health imposes a commitment to the health sector, first of all, with the quality of life of the populations that it works with. In this regard, public health research substantially contributes to the approach of this object, generating knowledge produced by its own methods, yet it is respectful of the different levels of anchorage and application.

In conclusion, though there is a hegemony of the position that defends a narrow and specific definition of the object of knowledge, as residually identified in the panorama of health research in Brazil today, all efforts should be driven to overcome this barrier, in order to develop a pluralist and interdisciplinary national science, more committed to social change and much closer to the health realities of this country. 


\section{Acknowledgements}

The authors thank Nancy Krieger, Juan Samaja, Rita Barradas Barata and Reinaldo Guimaraes for their invaluable comments on an earlier version of this paper. NAF received a CAPES Foundation Senior Fellowship while writing the final version of the manuscript.

\section{References}

1. Almeida Filho N. A Ciência da Saúde. Hucitec, São Paulo, 2000.

2. Bhaskar R. Scientific Realism and Human Emancipation. Verso, London, 1986.

3. Bourdieu P. La spécificité du champ scientifique et les conditions sociales du progrès de la raison. Sociologies et Sociétés 1975; VII(1):91-118.

4. Bourdieu P. Los Usos Sociales de la Ciencia. Nueva Visión, Buenos Aires, 2000.

5. Castoriadis C. As Encruzilhadas do Labirinto/3 (O Mundo Fragmentado). Paz e Terra, São Paulo, 1992.

6. Chalmers A. O que é Ciência Afinal? São Paulo: Brasiliense, 1995.

7. Chaves M. Complexidade e Transdisciplinaridade: Uma abordagem multidimensional do Setor Saúde. Revista da ABEM 1998;22(1):7-18.

8. Farmer P. Infections and Inequalities: The Modern Plagues. University of California Press, Berkeley, 1999.

9. Guimarães R., Lourenço R., Cosac. S. A pesquisa em epidemiologia no Brasil. Revista de Saúde Pública 2001;35(4):321-40.

10. Gonçalves R.B.M. Trabajo Médico y Prácticas de Salud. Siglo XXI, Mexico, 1989.

11. Kuhn T. The Structure of Scientific Revolutions. Chicago Univ. Press, Chicago, 1962.

12. Kuhn T. The Road since Structure. University of Chicago Press, Chicago, 2000.

13. Maturana H., Varela F. El árbol del conocimiento. Santiago, Editorial Universitária, 1984.

14. McQueen D. Perspectives on health promotion: theory, evidence, practice and the emergence of complexity. Health Promotion International 2000; 15:95-9.

15. Merrel F. Simplicity and Complexity. University of Michigan Press, Ann Arbor, 1998.

16. Porter J.D., Grange J.M. Tuberculosis: An Interdisciplinary Perspective. Imperial College Press, London, 1999.

17. Powers J. Philosophy and the New Physics. London, Methuen, 1982.

18. Prigogine I., Stengers I. La Nouvelle Alliance. Paris, Gallimard, 1986.
19. Rorty R. Objectivity, Relativism and Truth. Cambridge Univ. Press, Cambridge, 1991.

20. Rorty R. Philosophy and the Mirror of Nature. Princeton University Press, Princeton, 1982.

21. Samaja J. A Reprodução Social e a Saúde. Casa da Saúde, Salvador, 2000.

22. Samaja J. Epistemologia y Metodología. EUDEBA, Buenos Aires, 1994.

23. Schramm R.F., Castiel L.D. Processo Saúde/Doença e Complexidade em Epidemiologia. Cadernos de Saúde Pública 1992;8:379-90.

24. Vegetti M. Los orígenes de la racionalidad científica. Península, Barcelona, 1981. 